\title{
An Evaluation of the use of ICT within Primary
}

\section{Education in Malawi}

\author{
David Hollow and Paola Masperi
}

\begin{abstract}
The paper demonstrates how appropriate technology, when combined with quality curriculum-based content, has the potential to have a positive impact on primary education within developing countries. It documents an evaluation of portable learning technology from the Ministry of Education, Science and Technology in Malawi, providing theoretical background and educational context before detailing the methodology and findings of the study. Significant impacts from the introduction of the program were increased school attendance, reduced dropout rates and improved student and teacher enthusiasm. Alongside this, the audio and video material and interactive learning techniques offered potential pedagogical benefits in combining learner-centered and outcome-based activities with continuous assessment, helping children to retain information more effectively and record higher test scores. Major challenges were also identified regarding implementation and sustainability. These centered around the need for rigorous teacher training, classroom integration, appropriate deployment, maintenance, sustained impact and overall cost-effectiveness. In closing, the paper emphasizes the need for such programs to be driven by educational concerns and recognizes the similar challenges faced in many related initiatives.
\end{abstract}

Index Terms - Education, Evaluation, Malawi, Technology

\section{INTRODUCTION}

$I$ $\mathrm{N}$ setting the context for the subsequent evaluation the paper begins with an overview of two distinct spheres, firstly the current education context in Malawi and secondly the potential role of technology within education. These two seemingly disparate themes are brought together through the case study of the Interactive Learning Program. An overview of the program is provided, followed by an explanation of the methodological approach employed in the monitoring and evaluation exercise. The findings are then categorized into four sections of analysis which inform the concluding comments and recommendations.

The Interactive Learning Program in Malawi comes under

Manuscript received September 21, 2008

David Hollow is a $\mathrm{PhD}$ candidate with the ICT4D Collective in the Geography Department at Royal Holloway, University of London. e-mail: d.m.hollow@rhul.ac.uk

Paola Masperi is an independent development consultant, based in London. e-mail:paola@mayamiko.org the authority of the Ministry of Education, Science and Technology (MoEST). Funding for the initiative was provided by a British company who also developed the educational software for the portable devices.

\section{CONTEXT}

\section{A. Education in Malawi}

Free primary education was introduced in Malawi in 1994 as a result of the commitment made by the country at the World Conference on Education for All (EFA) in 1990. Widespread agreement exists regarding the vital place of education within poverty reduction efforts, capacity building and growth strategies of developing countries. In Malawi, numerous policy, budgetary and multilevel commitments have contributed to significant progress in the delivery of primary education since 1994. This includes enrolment figures rising from 1.9 million to 3.2 million, the construction of 1,000 new classrooms and roll out of the new curriculum to 5,500 schools [1]. However, Malawi is one of the poorest countries in the world, with a GNI per capita of \$230. Life expectancy at birth is 48 years and $63 \%$ of the population live on less than $\$ 2$ per day [2]. Within such a context of extreme poverty, the rapid advancements in access to free schooling have put the national education system under considerable strain.

The increase in enrolment has led to significant pressure upon primary schools in Malawi, most notably in regard to increasing class sizes, a lack of fully qualified teachers, limited teaching materials and inadequate infrastructure. It is estimated that an extra 8,000 teachers are currently required to meet the MoEST target pupil to teacher ratio of 1:60 [3]. In addition, and despite national net enrolment levels of $91 \%$, national drop out rates remain high with only $44 \%$ of those that enroll in Standard 1 completing Standard 5 and less than $30 \%$ reaching Standard 8, the final year of primary education [4]. Linked to this and demonstrating the ongoing challenge in regard to teaching capabilities and educational outcomes is a declining performance in national examinations with a failure rate of over $40 \%$ [1].

The importance of ensuring good quality education alongside improved access [5] has been long recognized in Malawi and in 1999 it was decided that a comprehensive 
reform of the curriculum was required due to the developments that had occurred since 1994 [3]. The relevance of topics such as democracy, human rights, gender and HIV/AIDS were increasingly acknowledged and these have been systematically incorporated into the new primary school curriculum in the form of life skills education.

\section{B. Technology in Education}

There is significant attention focused upon the potential for ICT to assist in leapfrogging educational challenges within developing nations [6] [7] [8], with much enthusiasm for a possible technology-enabled 'breakthrough in learning' [9]. However, much debate surrounds the question of whether the infusion of technology into education has actually instigated more than incremental changes to the field. Proponents assert that the last decade have resulted in the emergence of a new landscape for education across the globe [10] with technology positively effecting student motivation [11] and, when initiatives are implemented with fidelity, leading to a significant increase in learning [12]. This is challenged by those who argue that achieving structural technological change in schools takes much longer than anticipated [13] with no substantial evidence that the introduction of technology has yet caused any fundamental change in either a developed or developing context [14]. Wagner [15] notes a wide variety of outcomes from ICT for education projects in developing countries, with significant negative impacts including the reinforcing of dependencies, imposition without community involvement and collapse due to lack of funding or political commitment.

Within this contested environment, the range of technologies theoretically available for deployment within developing country educational contexts is rapidly expanding, with a transition towards increasingly portable, powerful and adaptable tools [16]. The new technologies available have potential to mark a significant transition beyond conceptualizing e-learning through conventional static computer laboratories [17], emphasising instead the place of anytime, anywhere computing [16] and mobile learning [18]. Such a shift creates opportunity for major changes in the application of educational technology, with key potential benefits noted as increased enthusiasm, cooperation, communication and student ownership [19].

Despite the potential benefits of learning technologies [20] it is important to recognize that not all solutions which have contributed to educational advancements in the developed world can simply be transferred to a developing world context. In order for the potential of ICTs to be realized in improving the quality of education it is important they are applied with cultural understanding, local knowledge and sensitivity [11] [21]. Indeed, 'effective use of ICTs must be tied to the needs of developing countries and challenge the one size fits all approach of many programmes' [19;7]. A recognition of this fact emphasises the need for primary focus on appropriate software development linked to curriculum- based content and sustained classroom integration.

\section{INTERACTIVE LEARNING PROGRAMME}

Having outlined the overall context of education within Malawi and the theoretical role of technology within education, attention now turns to the Interactive Learning Program. It considers whether the initiative constitutes a suitable application of portable technology to support the provision of basic education within the country. To begin, the specifics of the program are explained, including the background, technology and pedagogical rationale.

\section{A. Background to Program}

The Interactive Learning Program was introduced in 2006 and following initial positive feedback the MoEST requested, in early 2007, that the initiative be scaled up to incorporate 50 primary schools. The schools that the MoEST selected for participation ranged from Karonga District in the north through to the southernmost districts of Mulanje and Phalombe. A total of 520 custom-made handheld interactive learning aids were distributed to the participating schools. This totaled ten devices for each school, except for two test schools which received 20 devices for the purposes of targeted monitoring and evaluation.

\section{B. Technology Utilized}

The device in question is a handheld interactive learning aid (from herein referred to as the learning machine or gadget as named by the participating children), slightly larger than a mobile phone and able to play video and audio through either a loudspeaker or headphones. Positioned next to the screen are a selection of buttons which can be pressed in response to questions asked in the lesson being watched. The device has an in-built rechargeable lithium battery with power for between four and six hours of continuous play. A total of 25 lessons in Chichewa and 40 in English are preinstalled and stored on two gigabytes of internal Flash memory, leaving additional room for newly developed lessons to be incorporated. The lessons are designed for use by children in Standard 3, 4 and 5, each lasting approximately 20 minutes and covering a range of curriculum based subjects such as General Studies, Social Studies, Science, Mathematics, Geography, Life Skills and English.

With less than $5 \%$ of primary schools across Malawi estimated as having access to a reliable supply of mains electricity [3] the initiative was dependent upon solar charging systems. Each of the project schools were equipped with a 20Watt solar panel connected to a deep-cycle sealed battery, generating enough energy to power 20 of the learning machines. Teachers were given training regarding appropriate charging and usage, and instructed to leave the devices to recharge overnight once every two days. 


\section{Pedagogy}

The digital content on the learning machines is designed in order to enable and promote interactive and outcome-based learning, linked to the Malawi national curriculum and actively supporting the government Primary Curriculum Assessment Reform [22]. The lessons are designed to be user friendly, with the audio-visual content accessible to illiterate or semi-literate users. Instructions from lip synchronized cartoon characters explain the functions of the various buttons on the learning machine. Once a lesson title has been selected the methodology becomes interactive and learner-centered. Having listened to brief teaching points the learners are tested on their understanding of the information supplied through the posing of multiple-choice questions answered by pressing buttons on the device. At the end of the lesson learners are given opportunity to test what they have learnt through undertaking an overall quiz of ten questions where they are congratulated according to the score attained. This outcomebased approach provides incentive for the children to work conscientiously and allows the teacher to monitor progress.

The decision to include lessons in both Chichewa and English was taken on the basis that early learning content is most effective when communicated in the vernacular language [23] [24]. The dual language approach equips children for the challenging transition from Chichewa to English as the official medium of school instruction which takes place in Standard 5. The most conducive learning environment for using the devices is with groups of between four and six students. In this context team work, group participation and the development of leadership skills can each be encouraged.

\section{MethodologicAl APPROACH}

In regard to the overall context of technology within education, Kozma [25;21] concludes after assessing a wide variety of studies that there is "no consistent relationship between the mere availability or use of ICT and student learning'. Beyond such generic assertions, there are significant knowledge gaps remaining regarding what kind of initiative works and what does not. As InfoDev [11;5] summarize, 'despite thousands of impact studies, the impact of ICT use on student achievement remains difficult to measure and open to much reasonable debate'. In light of such observations all partners in the Interactive Learning Program initiative recognized the necessity for a comprehensive monitoring and evaluation exercise, the key objectives of which were to;

- assess the impact of the program on primary education

- assess the feasibility of the program in each test school

- identify program weaknesses for future refinement

- develop both teacher and organizational capacity

- provide feedback to partners regarding suitability of scaleup and sustainability

A common theme from ICT-enhanced education programs within developing countries is the marginalized place of monitoring and evaluation. Where undertaken, there is often strong emphasis placed on hardware-based input indicators [25] rather than more complex learning outcomes. In order to avoid this simplification and demonstrate an alterative approach, a rigorous monitoring, evaluation and impact assessment structure was built into the program throughout implementation. This involved three field visits from the monitoring and evaluation team in September 2007, November 2007 and March 2008.

In addition to being marginalized, monitoring and evaluation of ICT for education programs has rarely embraced creative processes of assessment [26]. Recognizing this, a systemsbased approach was utilized in designing the methodology [27] [28] [29]. This involved adopting a mixed- and multimethod approach which focused on process and aimed to engage with multiple stakeholders so as to gain a plurality of perspectives regarding program impact. It also ensured that data gathered was not solely anecdotal but credible, dependable and confirmable [30]. Within this overall aim for increased creativity and rigor, the research remained subject to the standard complexities and constraints of limited time, budget, data and personnel [31] [32].

It light of the constraints it was decided by the MoEST that five representative test schools would serve as a sample of the 50 participating in the program. The schools selected by the MoEST were Chin'gombe, Mwatibu, Mthentera, Mbinzi and Dzenza. None of these schools had any form of ICT incorporated into the curriculum prior to the introduction of the program. A total of 15 days were spent in these schools due to a recognition of the benefits of prioritizing classroombased research [33]. A combination of qualitative and quantitative methods were utilized and these are now outlined alongside the rationale for each.

A total of 15 lessons in which the learning machines were being used were observed throughout the process [34]. Teachers were asked to conduct the lesson as they would normally, without altering classroom arrangements. Observing usage of the technology in a normal environment provided an ideal foundation for the subsequent methods, giving opportunity to discuss successes and suggest ways to work around challenges with the children, teachers and headteachers.

Some 15 group interviews were held with children in the five schools, in order to hear what difference the program had made to their lives. The children were asked what they liked and disliked and improvements they would make for the future. The interviews followed a semi-structured, guided approach [35] [36] facilitated by a teacher and conducted in Chichewa. Participants were selected at random from Standard 3 and 4 classes, were aged between 7 and 15, and had equal gender representation.

Following these group interviews, more detailed conversations were held with individual children in order to learn about particular experiences or perspectives that they had expressed. Such unstructured and story-based conversation was useful in identifying unanticipated program 
impacts [37]. In addition to this, a three stage individual interview was conducted with the head-teacher of each school and also with four related officials from the MoEST. These interviews provided opportunity to obtain input regarding the program feasibility, impact and future direction.

Conducting focus groups was considered to be the most appropriate method to gain detailed feedback from teachers regarding their view of the program and the difference it had made to their lives, including positive and negative impacts and potential improvements. A total of 15 focus groups were conducted in this safe environment [38] which facilitated robust dialogue [39] but ensured no one felt pressurized to share personal experiences [40].

Building on these, the learning octagon was a research tool developed specifically for the program in order to stimulate more detailed discussion between teachers in the focus groups. The octagon providing a pictorial representation to assess the strengths and weaknesses of eight different dimensions to the program by drawing on a combination of the Octagon tool [41] and Most Significant Change approach [42] [43]. This enabled the teachers to collaborate on creating a visual representation of the impacts of the initiative.

In addition to these methods, and in order to enable ongoing monitoring on a weekly basis, one teacher from each of the five schools was selected to complete a diary documenting their experiences of using the learning machines in their lessons. The diaries were semi-structured and designed to provide a continuous record of particular strengths, weaknesses and challenges encountered.

Baseline tests were conducted at stage one and three of the research. The objective of the test was to provide a quantitative assessment of the impact of the program on the attainment of the children regarding both curriculum and lifeskills. In each of the five test schools there were 12 children randomly selected from Standard 3 and 4, providing a total of 60 children, 30 boys and 30 girls. Five additional schools were selected to act as a control group with an additional 60 children tested.

Alongside focusing on the test schools, evaluation questionnaires and equipment feedback forms were distributed to all 50 participating schools in order to gain a broader understanding of program impact. The questionnaires gave opportunity for feedback regarding patterns of usage and challenges encountered in implementation. The equipment feedback forms enabled the documentation of technical problems encountered throughout the program.

Each of the methods outlined above enabled a detailed perspective to be developed regarding the strengths and weaknesses of the program. The monitoring and evaluation methodology employed was participatory throughout [44] and engaged with children, teachers, headmasters, community leaders, government officials and civil society representatives. Each school was visited at least three times throughout the six month research period and this allowed for a progressive approach and the development of good relationships with a number of stakeholders.

\section{ANALYSIS}

The monitoring and evaluation exercise was focused on assessing three interconnected spheres which cut across the five previously identified research objectives. These were impact upon students, impact upon teachers and effectiveness of the technology. Analysis of each sphere is based on the data gathered using the range of methodological approaches previously outlined. The analysis is illustrated throughout with quotations from children, teachers, head teachers and MoEST officials.

\section{A. Impact upon Students}

In assessing the overall impact upon students the study considered the specific impact on four main areas of student attendance, enthusiasm, attainment in curriculum subjects and attainment in life skills subjects.

A significant and universally agreed impact of the program was the increase in school attendance. Teachers reported a large increase in class sizes with fewer children absent than prior to the intervention. One student from Standard 4 explained why this was the case:

Before the gadgets more pupils were absenting themselves from classes but now we encourage our fellow pupils to come to school and tell them, today if you absent yourself, you will miss using the gadgets. I used to absent myself $50 \%$ of the time before the gadgets came, now I come to school everyday.

This is a significant achievement within a national context of high drop-out rates and absenteeism. For any educational intervention to succeed it is necessary for learners to be attending school on a regular basis and the motivating influence of appropriate technology is clearly a contributing factor in achieving this desired end. Despite strong anecdotal evidence, assessing the statistical significance of the change in attendance was hampered by a lack of daily attendance records maintained in each school, meaning it was impossible to track exact attendance patterns prior to the current term.

Children in the group interviews reported that they were enthusiastic about coming to school now that they were using the learning machines. Several students reported having shared the experience with family and community members who actively encouraged them not to miss out on the opportunity to learn with the new technology. As one student from Standard 3 explained:

They [parents] said to me that you have to work hard and make sure you do not run away from lessons when you are using the computer. I used to run away from class but now I have changed my behavior ... because I am attracted to the gadgets and if I miss the chance to use it, it will never come again.

Other children emphasized what they had learnt through the lessons and how this related to what they hoped to do in the future. One student from Standard 5 reported the impact of a particular lesson regarding counting: 
Now I know how to add and subtract - I could see the pictures and I was able to subtract. This makes a foundation for me to be able to work in a bank - this is what I want to do in the future.

The learning machines are perceived by the children as a mixture between mobile phones, games devices and video players. This makes them attractive to the children, who quickly become familiar with them and enjoy the process of being congratulated by the device for answering questions correctly. Observed learners appeared to enjoy working in groups and taking turns in pressing the buttons. Teachers also noted a similar impact and emphasized the improved listening skills of the students:

They are able to explain things now - and the gadgets really help them with listening skills - if they do not listen then they miss what has been said and they cannot answer the question - and it makes them be fully attentive.

Increased attentiveness in class and greater motivation to attend school also had an effect on the attainment of the children in both curriculum and life skills based lessons. Both students and teachers reported that the use of audio and video, as well as the continuous assessment quizzes, increased retention and affected attainment. One teacher reflected on tests completed the previous week:

We had the mid-term tests last week and more pupils did well than before - when I asked them why they said it was because of the gadgets - 'we just remember what we have learnt on them'. The increase in attainment has gone up by about $30 \%$ on average from what they normally achieve.

Despite such assertions it was difficult to assess quantitative impact on student attainment due to the short period of time since the beginning of the intervention. A comparison of scores between the baseline and second test demonstrated that certain sectors of the curriculum had considerably more correct answers after using the learning machines. However, the majority of students had only completed $15 \%$ of available lessons at the time of the second test and the overall improvement in curriculum attainment was limited to $1.5 \%$. Similarly, improved attainment in life skills was difficult to quantify as test scores related to knowledge gained rather than necessarily to behavioral and lifestyle change. The overall impact on life skills attainment in the baseline test was a 3\% improvement. Again, the questions which were answered correctly indicated an increased understanding of the content for those lessons which the teachers had chosen to use most regularly.

Although quantitative change proved difficult to assess, many students interviewed were able to recall accurate information on the life skills lessons they had used and expressed satisfaction to have learnt skills useful to their daily lives. Learners explained how they had put into practice what had been taught in the lessons, indicating potential behavioral change:

[my favorite lesson was...] Preventing malaria - because it affects many children in the village. I learnt that we must sleep under treated bed nets and must not play with stagnant water. I did not know this before the gadgets.

Children were also able to talk about culturally sensitive subjects such as HIV/AIDS and explain what they had learnt from the lessons. Teachers stressed the value of the interactive lessons in a cultural context where such discussions are often considered taboo. The children requested that new content be added to the devices so that they could learn about a greater variety of topics. The most commonly requested subjects were Agriculture, Mathematics, English, Religious Education, Science and Technology, Physical Education and Music. Similarly, the teachers requested that new content would remain linked with the curriculum reform in order to provide them with support in this transition.

The impact of the initiative on the students is intrinsically linked to the way in which the teachers are affected, and this is now considered.

\section{B. Impact upon Teachers}

In assessing the overall impact upon teachers the study considered two factors, teacher enthusiasm and teacher workload.

The majority of teachers were enthusiastic about the introduction of the program into their school and several commented that they felt honored to have been selected as a school for the pilot. They were pleased that MoEST officials were visiting their school and showing an interest in their work. They were keen to learn about technology and could see the positive effects on themselves and the learners. They also noted how the introduction of the learning machines had helped them in altering their teaching style, adopting new and innovative approaches:

We love it - before the gadgets it was just talk and write for some subjects - but now the kids can see the pictures. Some of the children can be sitting doing one thing while others are doing the gadgets.

Young trainee teachers particularly enjoyed using the technology and often engaged in using it without apprehension. This confidence had a clear effect on the manner in which the children approached the devices and made use of them in the classroom. The enthusiasm of the students also affected the teachers:

...because if the learners are enthusiastic then it makes us enthusiastic. If the gadgets help the students to learn then the teachers have to be happy that the students are doing well.

However, this enthusiasm was not felt universally. Mature teachers often showed less interest in the program, were fearful of using the technology and reluctant to let the children use it independently. In one of the test schools after six months of usage there were only three teachers still using the learning machines. All the other teachers in the school had become uninterested in the program, considering the additional workload to be too much of a burden.

The teachers reported a variety of different experiences regarding the impact of the program on their workload. This was dependent upon the manner of implementation in each 
school and the degree to which the learning machines were incorporated within the lesson schedule. The overall feeling from the teachers was that the introduction of the gadgets had increased the workload in certain areas and decreased it in others:

There are two things, lesson preparation - for this it might take more effort - and lesson delivery - for this it might take less time. It has made us do more work - we have to guide the students. And there are not enough gadgets - so if we had enough gadgets then it would be ok and then it would not increase our workload.

Since the intervention was a pilot project the majority of schools chose to use the gadgets after the school day had finished so as not to interfere with the daily timetable. This meant that the teachers were required to stay in school for an extra hour every day to facilitate the lessons. Most were willing to do this but some expressed reluctance due to preexisting after-school commitments. It was also commented in two schools that the initiative resulted in more preparation work for the teachers because they needed to become fully familiar with the devices themselves before making use of them in lessons with the children. In the two schools where the teachers had chosen to incorporate the gadgets into the school day then a decrease in workload was reported. In these cases the gadgets helped with effective facilitation, the management of large classes and provided support in preparing teaching and learning materials for the lessons.

In light of this, the program would benefit from the development and distribution of a pedagogical guide for teachers regarding the effective integration of the learning machines into the learning routine of the children. Teachers should also be encouraged to utilize the full range of lessons that are available on the devices. This would complement the development of a schedule for teachers to use the machines during school time, giving clear explanation how it can most appropriately support the curriculum.

The increased ability of the children to memorize what had been taught was also recognized to make the job easier by one teacher from Standard 4:

Gadgets have simplified the work for the teachers - when the child sees something he remembers - when he just hears he forgets. When they see it, it stays in their mind.

Others noted that the impact of the learning machines in encouraging so many children to return to school had caused class sizes to expand significantly, resulting in more work attempting to manage the children. A common concluding comment from teachers was that the workload would decrease significantly if there was a lower pupil to gadget ratio and if the lessons on the gadgets were fully compatible with the syllabus and incorporated into the curriculum. The program would therefore benefit from an increased allocation of 20 learning machines per school. This would facilitate a more concentrated impact and allow a greater number of children in smaller groups to benefit from the content on the devices.

In light of the challenges presented, it is clear that regular training sessions for the teachers would assist in maintaining the momentum of the program and improving teacher motivation. The limited budget of the MoEST makes it a constant challenge to deliver adequate training, especially in remote areas. The teachers requested opportunity to ask questions and provide feedback, requiring effective communication channels between the stakeholders. As highlighted by one official:

If you come back frequently then the schools will know you are coming and they will keep using the gadgets but if they think no one is coming to visit them then they will forget to use them. This is because when they are monitored they will feel that somebody is appreciating their job - they are happy that they can be involved and they see that somebody cares.

The feedback from teachers demonstrated that sustained monitoring from MoEST officials constituted a significant capacity building process. The impact was especially pronounced in marginalized rural areas which were inaccessible and rarely visited. In light of this is it clear that a continuing focus on teacher training which both develops skills and instills value is intrinsic to the success of this and any ICT for education initiative. The ability of the teachers to utilize technology with confidence and adapt it to the specific needs of the classroom is a central determining factor. Without this integration any initiative remains an appealing add-on but does not have significant effect on the culture of the classroom, pedagogy, or rationale for learning.

\section{Effectiveness of the Technology}

The success of the initiative, whilst not determined by the technology, was dependent upon it operating effectively within each school. Usability, durability and the reliability of the devices and charging solution were the three areas assessed in the study.

The lesson observations demonstrated that the majority of children were able to operate the learning machines independently, understanding the purpose of the buttons and completing quizzes without supervision. The process of lesson selection occasionally required guidance from teachers but this was rarely necessary because the most capable children were seen to take a lead in the learning groups, demonstrating considerable confidence with the devices. However, a significant factor limiting usability was the low number of devices per classroom and subsequent high number of students per group, on occasion as many as ten learners. This was not conducive to learning as the machine is designed for small groups, with small screen and quiet audio output. In such situations, dominant children were observed bringing the machine to their ear in order to hear the lesson, meaning other children were unable to engage and became easily distracted. This was confirmed by a participating official from the MoEST who noted:

Bringing such technology is very important - it is only that at the moment the gadgets are very few - there needs to be more. It is important that you have the right number of gadgets for the number of children because it is difficult for so 
many children to share.

Due to the nature of such a pilot program it was anticipated that there would be significant problems regarding device durability. However, after six months of usage only $8 \%$ had developed problems, the majority being due to software issues easily resolved through reformatting. Two of the devices stopped working due to the on/off switch breaking, these were repaired in situ and left fully functioning. A major concern in this respect was that teachers often assumed they had broken the devices when all that was actually required was for them to be charged fully.

The solar panels operated effectively in each of the five test schools throughout the program with all of them maintaining adequate power to charge the devices as often as necessary. Several program schools outside the five included in the test did report problems including two faulty batteries, one loose connection and one stolen panel. In addition to these, one school adopted the practice of disconnecting the battery from the panel to remove it for safe keeping during the night and this prevented the battery from charging fully.

\section{CONCLUSIONS}

The analysis of impact on students, teachers and technological effectiveness has demonstrated the educational potential of the Interactive Learning Program. The introduction of the devices had significant positive impact upon school attendance and levels of enthusiasm. Also noteworthy was the increased value placed on teachers and the role of education within the community. However, alongside this, considerable challenges were encountered including the negative impact on teacher workload, lack of classroom integration, significant infrastructural constraints and the necessity for further teacher training. The future success, sustainability and potential for project scalability is dependent upon engaging with each of these identified challenges. The observations made in the analysis speak directly to the program efficacy but are also applicable lessons for ICT for education initiatives more widely. The introduction of technology into education systems in the developing world is a complex procedure with considerable potential for failure and therefore it is vital that rigorous monitoring and evaluation is incorporated throughout all such initiatives.

The price of portable educational technology is constantly decreasing, making initiatives such as the Malawi Interactive Learning Program increasingly cost effective. The September 2008 price of each learning machine was circa US\$55 and as each device can be used by several children the per child cost is considerably lower than other widely publicized solutions. Significant future potential also lies in the opportunity for integrating the educational content with new generation mobile phones and other handheld devices becoming progressively more available across the region. Linked to this, increased ability to send and receive data in standard formats (for example Macromedia Flash, xml, mp3 or mp4) will allow for the development of user interaction. Market influences on the development of mobile technology also ensure sustained improvements in hardware capabilities and the subsequent emergence of new educational possibilities.

However, within all such initiatives, it is necessary that the application of technology is conceptualized as a tool in facilitating the overall aim of catalyzing a more fully effective approach to education. In reaching this goal many of the challenges documented remain the same regardless of the presence of technology.

It is not overly surprising that the introduction of ICT into primary schools in Malawi caused a dramatic increase in attendance figures. The significant question for ongoing research remains one of long term impact on approach to schooling, once initial enthusiasm surrounding the program has subsided. Whilst a significant achievement, increasing school attendance figures is not the most significant long-term challenge facing education in Africa [5]. Instead, it should constitute an initial building block which can be capitalized on through adopting an integrated approach to developing the capacity of the education system. One dimension to this will be the effective utilization of curriculum enhancing technology, such as the Interactive Learning Program. For full benefits to be realized, such programs require transition from their position of peripheral curiosity to one of being integrated as a sustainable teaching tool. Future research is required to assess the degree to which this is occurring in Malawi.

A variety of different solutions are required to address the challenge of providing equitable access to good quality education in the developing world. The increasing availability and decreasing cost of portable devices ensures that they are likely to play a prominent role in the future, however this should not lead to such technologies being presented as an educational panacea. For programs to be of maximum educational benefit in Malawi, as in many such initiatives, the critical issues for consideration and action remain pedagogy, classroom integration and teacher training.

\section{REFERENCES}

[1] MoEST, Link for Education Governance. Education Sector Performance Analysis. Lilongwe, Malawi. 2007.

[2] World Bank, Data and statistics: Malawi. 2006 www.web.worldbank.org Accessed 21/08/08

[3] MoEST, Primary Curriculum and Assessment Reform (PCAR). Implementation Plan 2007-2010, Lilongwe, Malawi. 2008.

[4] UNESCO, Institute for Statistics, country data 2008. www.uis.unesco.org Accessed 21/08/08

[5] EFA, Global Monitoring Report: The quality imperative. 2005. www.portal.unesco.org/education Accessed 21/08/08

[6] D. Pye and J. Stephenson, Using ICT to Increase the Effectiveness of Community-based, Non-formal Education for Rural People in SubSaharan Africa: the CERP Project Final Report (DFID Educational Paper 50). London: Department for International Development 2003.

[7] V. Tinio, ICT in Education. E-Primers for UNDP, New York 2003.

[8] J. Leach, DEEP IMPACT: an investigation of the use of information and communication technologies for teacher education in the global south. Researching the Issues, 58. DFID 2005.

[9] D. Wagner, Monitoring and evaluation of ICT for Education: An Introduction. Chapter 1 in: D. Wagner et. al. 2005. Monitoring and 
Evaluation of ICT in Education Projects - A Handbook for Developing Countries, InfoDev 1-19, 2005.

[10] D. Keats, The genesis and emergence of Education 3.0 in higher education: the potential for Africa. First Monday 12, 3, 2007.

[11] InfoDev, Knowledge Maps: ICTs in Education. World Bank 2005.

[12] C. Fadel and C. Lemke, Technology in Schools: What the research says. Metiri Group, Commissioned by Cisco Systems 2006.

[13] L. Cuban, Oversold and Underused - Computers in the Classroom. Harvard: USA 2001.

[14] T. James and J. Miller, Developing a Monitoring and Evaluation Plan for ICT in Education. Chapter 4 in: D. Wagner et. al. 2005. Monitoring and Evaluation of ICT in Education Projects - A Handbook for Developing Countries, InfoDev. 57-77 2005.

[15] D. Wagner, B. Day, J. S. Sun, Recommendations for a pro-poor ICT4D non-formal education policy. Final Report for, Imfundo: Partnership for IT in Education, DFID, 2004.

[16] M. Sharples, Disruptive Devices: personal technologies and education. Educational Technology Research Paper Series 11, The University of Birmingham, 2000.

[17] H. U. Hoppe, R. Joiner, M. Milrad and M. Sharples, Wireless and Mobile Technologies in Education. Journal of Computer Assisted Learning, Guest editorial, 19, 3, 255-259, 2003.

[18] F. Lehner and H. Nosekabel, The Role of Mobile Devices In E-Learning -First Experiences With A Wireless E-Learning Environment. WMTE 103-106, 2002

[19] J. Leach, T. Power, R. Thomas, X. Fadani and A. Mbebe, 4D Technologies: appropriating handheld computers to serve the needs of teachers and learners in rural African settings. Centre for Research and Development in Teacher Education, Open University: UK, 2003.

[20] C. Pontefract, Learning to Share, Insights Education 1 Missing the Connection - using ICTs in Education, February 2003

[21] R. Dhanarajan, Learning Technologies, where is the challenge? Education, Communication, Information 1, 1 Spring 2002

[22] MoEST, Primary Curriculum and Assessment Reform (PCAR). Literature Review of Primary Education in Malawi, Lilongwe, Malawi, 2002.

[23] G. Bunyi, Rethinking the place of African indigenous languages in African education. International Journal of Educational Development 19, 4-5, 337-350, 1999.

[24] EFA, Global monitoring report: Literacy for Life, 2006. www.portal.unesco.org/education Accessed 21/08/08

[25] R. Kozma and D. Wagner, Core Indicators for Monitoring and Evaluation Studies for ICT in Education. Chapter 3 in: D. Wagner et al. 2005. Monitoring and Evaluation of ICT in Education Projects - A Handbook for Developing Countries, InfoDev. 35-57, 2005.

[26] J. Taylor and S. Soal, Measurement in Development Practice: From the Mundane to the Transformational. Chapter 5 in L. Earle (ed) 2004. Creativity and Constraint: Grassroots Monitoring and Evaluation and the International Aid Arena. INTRAC Policy Series 18, 95-110, 2004.

[27] P. Morgan, Measuring the Development of Capacity: Is this Still a Good Idea? Chapter 2 in L. Earle (ed) 2004. 'Creativity and Constraint: Grassroots Monitoring and Evaluation and the International Aid Arena'. INTRAC Policy Series 18, 47-62, 2004.

[28] D. Watson, Monitoring and evaluation of capacity and capacity development. ECDPM, Discussion paper 58B. April 2006

[29] D. Cabrera, A Theory of Systems Evaluation. Systems evaluation and evaluation systems whitepaper series. New York: Ithaca, Cornell University, 2006.

[30] J. Baxter and J. Eyles, Evaluating qualitative research in social geography: establishing 'rigour' in interview analysis. Transactions of the Institute of British Geographers, 22, 4, 505-525, 1997.

[31] M. Bamberger, J. Rugh and L. Mabry, Real World Evaluation. Working Under Budget, Time, Data and Political Constraints. London: Sage, 2006.

[32] D. Gray, Doing Research in the Real World. California: Sage 2004.

[33] M. C. O'Sullivan, What is happening in the classroom? A commonsense approach to improving the quality of primary education in developing countries. Teacher Development, 9, 3, 301-314, 2005.

[34] J. W. Creswell, Educational Research: planning, conducting, and evaluating quantitative and qualitative research. New Jersey: Pearson Education, 2005.
[35] J. Burgess, The Art of Interviewing. In: A. Roger and H. A. Viles, (eds) The Student Companion to Geography. Blackwell: Oxford, 242-249, 2003.

[36] M. Q. Patton, Qualitative Research and Evaluation Methods. California: Sage, 2002.

[37] R. Chambers, Participatory Workshops - a sourcebook of 21 sets of ideas and activities. United Kingdom: Earthscan, 2002.

[38] G. Valentine, Being seen and heard? The ethical complexities of working with children and young people at home and at school. Ethics, Place and Environment. 2, 141-155, 1999.

[39] D. Stewart and P. Shamdasani, Focus Groups: Theory and Practice. Newbury Park: Sage, 1990.

[40] P, Bhattacharjee, Stepping Stones - A participatory tool to integrate gender into HIV/AIDS work. Development in Practice, 10, 5, 691-694, 2000.

[41] Sida. The Octagon. A tool for the assessment of strengths and weaknesses in NGOs, 2002

[42] P. Sigsgaard, Monitoring without indicators: an ongoing testing of the MSC approach. Evaluation Journal of Australasia. 2, 1, 2002.

[43] J. Dart \& R. J. Davies, A dialogical story-based evaluation tool: the most significant change technique, American Journal of Evaluation. 23, 2, $137-155,2003$

[44] M. Huberman, The Many Modes of Participatory Evaluation. Chapter 7 in J.B. Cousins and L. M. Earl (eds) 1995. Participatory Evaluation in Education. Studies in Evaluation use and organisational learning. London: Routledge, 103-114, 1995. 